\title{
Siân Jaggar: from porter to consultant
}

\author{
The consultant in adult and paediatric cardiothoracic anaesthesia is passionate about medical \\ education and Arsenal football club
}

\section{Full circle}

I've gone from being porter to consultant in the same trust. My first ever job was as a porter in Harefield hospital aged 16. I only got the job because they didn't realise that Siân was a girl's name. They tried to tell me that it would be too difficult and the male porters wouldn't like it, but I told them that wasn't reasonable and they asked me for an interview. I was the first female porter they ever appointed.

\section{Teaching}

I'm the only medic in my family, everyone else is a teacher. The only thing I knew when I was at school was that I wasn't going to be a teacher. Not because I didn't like teaching, I loved it, I just wasn't going to do what was expected of me. It seems stupid now because my biggest interest, outside of my clinical work, is education.

\section{Sexism}

After my house jobs I almost gave up medicine. I worked for a consultant who wouldn't talk to me if I wasn't wearing a dress. If I wore trousers we would have these bizarre ward rounds where I would discuss a patient, he would turn to the sister and ask her questions, she would look at me, and I would answer. If I was in a skirt he spoke directly to me.

\section{Anaesthesia}

Originally I wanted to work in an emergency department and I thought it would be useful to do some medicine and anaesthetics so I applied for a year of anaesthetic rotations. Within a month I knew that was what I wanted to do. It's got everything, from long term chronic pain management to obstetrics, where you're caring for people during a fantastic moment in their life and you've also got really acute physiology. There is something for everyone in anaesthesia. I can't imagine why anyone would want to do anything else.

\section{Research}

I did my higher degree in neurophysiology of pain, partly for interest, but also because I wanted to be able to talk to trainees about the advantages and disadvantages of research as part of anaesthesia training, and therefore I needed to understand the process. It was two years of full time research, partially supported by assisting a consultant cardiac anaesthetist in the private sector, which also kept my clinical skills up to date.

\section{Canada}

While I was a senior registrar at Royal Brompton Hospital one of the paediatric anaesthetic consultants was contacted by Sick Kids in Toronto to say they needed fellows in paediatric intensive care. I went out there for six months and I loved it-I didn't want to come back. With Toronto you're in a city but at the same time you can go out for a day of skiing or do water sports on the lake. I adored it, but it didn't have my dream job.

\section{Consultant post}

I now have my dream job at Royal Brompton and Harefield NHS Foundation Trust, where I look after both children and adults. There's a view that children have to be looked after in children's hospitals and adults in adult hospitals, but the whole life model may also be worthwhile. At Royal Brompton I have looked after adults who I cared for when they were children. We are the biggest cardiothoracic unit in Europe but it feels like a little hospital, as I know most people (including porters) by name.

\section{Perceptions}

People so often say, "You went into anaesthetics because you don't like talking to people," but that's absolutely wrong. I often meet my patients for just 10 or 15 minutes, at the scariest time of their lives, and I've got to convince them, or their family, that I'm going to keep them safe. Anaesthetists have to be great communicators because we've got to be able to meet people at the worst moment and make it ok for them.

\section{Outdoor living}

Although I work and trained in London, I'm not a city person. My holidays are spent trekking, canoeing, skiing-outdoors type stuff. I've hiked in the Ethiopian mountains and I've climbed Kilimanjaro. I'm also a big football fan and support Arsenal week in, week out from the stands, which can be an emotional rollercoaster, but certainly helps with resilience. 


\section{Career timeline}

2017-current Lead for appraisal, video, and audit, primary, Royal College of Anaesthetists exam

2017-current External examiner (anaesthesia), Aga Khan University,

Nairobi

2016-current Medical school entry interviewer, Imperial College London

2015-current Training programme director, specialty trainee years 3 and 4, Imperial School of Anaesthesia, London

1999-2004 Certificate of medical education, Dundee, undertaken by distance learning

2001-current Consultant, Royal Brompton Hospital, London.

Clinical fellow, paediatric intensive care unit, Hospital for Sick Children, Toronto, Canada

MD, Imperial College London

1998-2000 Specialist registrar rotation, North West Thames

1996-98 Research fellow, Imperial College School of Medicine, and

honorary senior research fellow, St Mary's Hospital, London

1995-96 Pain relief fellow and honorary senior research fellow, St Mary's

Hospital, London

1992-95 Registrar rotation, St George's Hospital, London

1991-92 Senior house officer rotation (anaesthesia), St George's Hospital, London

1990-91 Senior house officer rotation (medicine), Whittington Hospital,

London

1985-88 MBBS, University College London

1984-85 BSc (Biochemistry), University College London 


\section{Figure}

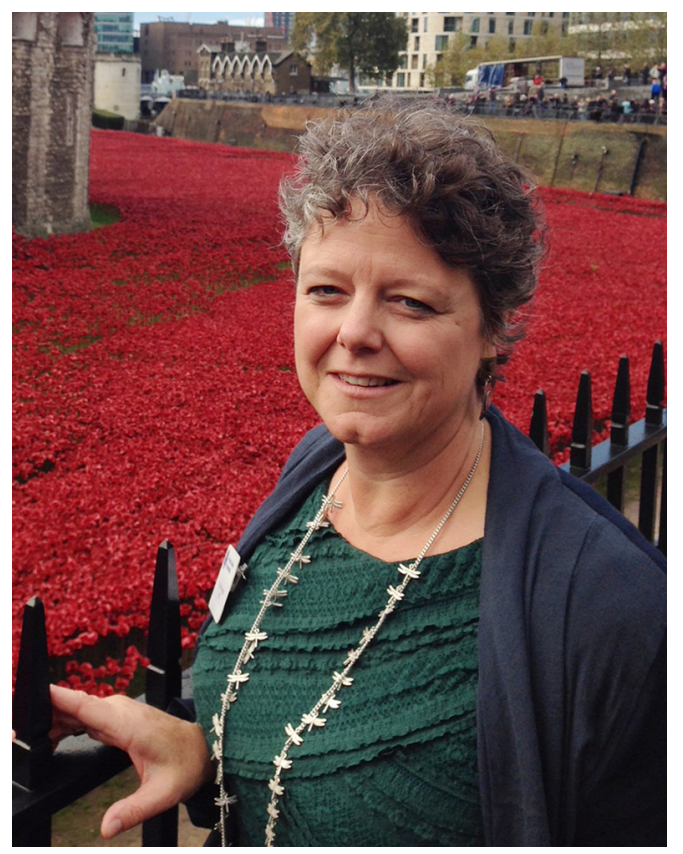

